\title{
Rauwolfia and Guanethidine: Pharmacology and Clinical Use in Treatment of Hypertension*
}

\author{
James Conway, m.D.
}

Ann Arbor, Michigan

B Y COINCIDENCE, reserpine, which is the oldest and weakest, and guanethidine, which is the latest and most potent of the modern antihypertensive drugs, share a common basic pharmacologic action. Both agents lead to depletion of the body stores of norepinephrine and thus, to varying degrees, interference with the function of the sympathetic nervous system. ${ }^{1-4}$ The precise mechanism by which they prevent the storage of norepinephrine is unknown, but evidence for its immediate release is seen in the transient rise in blood pressure and cardiac output after intravenous injection of guanethidine. ${ }^{4}$ Reserpine produces no such acute changes in man, but a similar release has been observed in animal preparations. ${ }^{5,6}$

Since both these agents lead to depletion of the sympathetic transmitter substance, the vascular smooth muscle retains its responsiveness to norepinephrine; indeed, an increased sensitivity is observed. The pressor effect of certain vasoconstrictor drugs, howcver, is diminished. These drugs-such as tyramine, amphetamine and ephedrine-depend for their action upon the presence of stored catecholamines in the tissue. $^{7-9}$

While guanethidine and reserpine share a similar mode of action, some important differences in their pharmacologic properties must be recognized. Guanethidine appears to produce actual blockade of adrenergic neurones in addition to depleting catecholamines. It does not cross the blood-brain barrier; hence its effects are confined to the peripheral sympathetic nervous system. Furthermore, in contrast to reserpine, it does not result in depletion of the catecholamine content of the adrenal medulla. ${ }^{10}$ Reserpine, on the other hand, crosses the blood- brain barrier and depletes cerebral stores of norepinephrine"l as well as those of hydroxytryptamine (serotinin). ${ }^{12}$ To this may be attributed its sedative and psychologic and certain endocrine effects. ${ }^{13}$

Therefore it was originally believed that the site of action of reserpine was a central one, probably in the hypothalamus. ${ }^{14}$ However, the observation that at lower doses of reserpine. the peripheral stores of norepinephrine are more depleted than the central ones ${ }^{15}$ has led to the conclusion that, as far as its hypotensive action is concerned, the main site of action of reserpine might be a peripheral one.

While the pharmacologic mode of action of reserpine and guanethidine tend to be similar, their clinical effects are conspicuous by contrasts rather than by comparisons.

\section{Reserpine: Gilinical Effects}

Reserpine is a mild antihypertensive agent. In oral doses of 0.8 to $1.5 \mathrm{mg}$./day a reduction of approximately $17 / 11 \mathrm{~mm}$. $\mathrm{Hg}$ in blood pressure has been found in two controlled doubleblind studies. ${ }^{16,17}$ Both the recumbent and standing pressures are affected without reduction in cardiac output, ${ }^{18}$ renal blood flow, glomerular filtration rate $^{19}$ or cerebral blood flow. ${ }^{20}$ The reduction in pressure progresses slowly over a period of weeks and persists for a similar period after the drug has been discontinued.

The side effects of reserpine (Table $\mathrm{I}$ ), although few and comparatively infrequent, are nonetheless serious since their gradual onset may delay detection; mental depression has been severe enough to result in suicide. Consequently, it is recommended that the maximal oral dose for long-term therapy should be limited to 0.5

\footnotetext{
* From the Department of Internal Medicine, University of Michigan Medical Center, Ann Arbor, Michigan. Author is an Established Investigator, American Heart Association.
} 
TABLE I

Side Effects of Reserpine

\author{
Nasal stuffiness \\ Increased appetite and weight gain \\ Fluid retention \\ Increased gastric acidity with possible \\ aggravation of peptic ulcer \\ Diarrhea \\ Vascular collapse under anesthesia \\ Nightmarcs \\ Depression \\ Drowsiness \\ Tremor
}

mg./day. The reduced antihypertensive effect of the smaller dose can to some extent be offset by simultaneous use of a diuretic agent.

Clinical Application: Reserpine therefore can be recommended for the milder cases of hypertension in which the diastolic pressure does not exceed $105 \mathrm{~mm}$. Hg. Oddly enough, parenteral reserpine (1-3 mg. intramuscularly) can be recommended in emergencies. The gradual fall in pressure over a period of 3 to 4 hours is rarely excessive in degree, and the minimal effect on renal function is ideal for the severely hypertensive subject. The accompanying sedation, however, may make the neurologic assessment of the patient difficult. Therefore, in the presence of hypertensive encephalopathy or cerebrovascular disease it is wiser to use a shortacting ganglion-blocking agent like camphodium (Arfonad ${ }^{\circledR}$ ) or parenteral pentolinium.

\section{Guanethidine: Cilinical Effects}

In contrast to the gentle if insidious effects of reserpine, guanethidine is rough hewn, producing extensive sympathetic blockade and consequently more obtrusive side effects.

The onset of action is quite slow. It takes a few hours to achieve maximum blockade after
TABLE III

Side Effects of Guanethidine

A. Attributable to hypotensive action:

1. Fatigue, weakness and lassitude (especially in morning or after exercise)

2. Dizziness

3. Syncope

4. Nitrogen retention

B. Nonspecific:

1. Diarrhea

2. Fluid retention

3. Depression

4. Nasal stuffiness

5. Parotid pain

6. Failure of ejaculation

7. Muscle tremors

parenteral injection. Intestinal absorption is incomplete, and the excretion of its metabolites is prolonged, only 24 per cent appearing in the urine 24 hours after a single oral dose. ${ }^{21}$ Therefore, two to three days are required to achieve a steady response with oral dosage. The effect on the blood pressure, like that of other autonomic blocking agents, is evident mainly in the standing posilion.

Guanethidine produces its hypotensive action by reducing both cardiac output and total peripheral resistance in recumbent position. There is also a small reduction in inulin and PAH clcaranccs. ${ }^{22}$ On physical cxcrtion the blood pressure may fall further in patients taking large doses of guanethidine, ${ }^{23}$ almost certainly because normal vasoconstriction fails in inactive vascular areas while dilation is occurring in the active muscles. The fall in pressure occurs in spite of an increase in cardiac output during exercise. ${ }^{24}$

Hypotensive Effects: The fall in blood pressure on standing is a frequent cause of difficulty. The standing blood pressure is lowest in the morning on arising ${ }^{21,25}$ at which time patients

TABLE II

Therapeutic Effect of Guanethidine in 11 Hypertensive Patients

\begin{tabular}{|c|c|c|c|c|c|}
\hline & \multicolumn{4}{|c|}{$\begin{array}{l}\text {-Blood Pressures- } \\
(\mathrm{mm} . \mathrm{Hg})\end{array}$} & \multirow{2}{*}{$\begin{array}{c}\text { Mean Dose } \\
(\mathrm{mg} \cdot / \text { day })\end{array}$} \\
\hline & A.M. & P.M. & A.M. & P.M. & \\
\hline Before treatment & $190 / 114$ & $171 / 122$ & $202 / 121$ & $199 / 122$ & \\
\hline After treatment & $166 / 104$ & $181 / 112$ & $138 / 95$ & $166 / 110$ & 60 \\
\hline Effect & $-24 /-10$ & $+10 /-10$ & $-64 /-26$ & $-33 /-12$ & \\
\hline
\end{tabular}


frequently complain of fatigue, lassitude, and then may faint quite suddenly. Since the difference between the standing and recumbent pressures decreases as the day progresses, this effect may be missed when the patient attends the physician's office. It has further been shown that hypotensive effects of exercise are greater in the morning than later in the day. ${ }^{21}$ The magnitude of the effect both on the recumbent and standing pressures varies considerably from one patient to another as does the dosage required. A mean dose of $60 \mathrm{mg}$./day in a group of 11 hypertensives recording their blood pressures at home produced a mean reduction of $34 / 10 \mathrm{~mm} . \mathrm{Hg}$ recumbent and $68 / 17 \mathrm{~mm}$. $\mathrm{Hg}$ standing in morning readings. By the evening there was a mean increase of $15 / 8 \mathrm{~mm}$. $\mathrm{Hg}$ recumbent and $25 / 5 \mathrm{~mm}$. $\mathrm{Hg}$ standing pressure ${ }^{24}$ (Table II). The cause of this loss of therapeutic effect during the day is unknown.

Although they have similar effects on the blood pressure, there is no relationship between the sensitivity of the blood pressure to ganglionblocking drugs and guanethidine, but little evidence has been seen for the development of tolerance with the latter.

The chief disadvantage of guanethidine, therefore, is that in many patients it is impossible to maintain an adequate reduction in recumbent prcssure without unbcarable postural symptoms in the morning. Furthermore, if the pressure rises much during the day, the expected benefit from the drug will be limited to a very short period of time.

Side Effects: In addition to its hypotensive effect, guanethidine produces certain nonspecific effects (Table III); diarrhea ${ }^{21,23,26}$ has been the most prominent. From our own experience and from a review of the literature, diarrhea appeared to occur whenever the dosage of the drug was high or was increased rapidly. Weight gain or edema has been observed, ${ }^{21,23,26}$ and mental depression has been reported, as have parotid pain, nasal stuffiness, failure of ejaculation and muscle tremors. The cause of these side effects is not understood, but they are readily reversible by reducing the dosage or withdrawing the drug.

Clinical Application: At present the most powerful antihypertensive agents are the autonomic blocking agents. Of these guanethidine is undoubtedly the most effective in relation to its nonspecific side effects. This drug is, thercfore, required by most patients with severe hypertension. The gradual onset of action and prolonged effect, however, make the drug unsuitable for use in emergency cases.

Side effects can be minimized by increasing the dosage gradually: $12.5 \mathrm{mg}$./day is the best initial daily dose increased to $25,50,75,100$ or $150 \mathrm{mg}$./day in weekly steps until the required effect is reached. If this gradual program is thought to be dangerously slow for the patient with severe disease, it is preferable to supplement it temporarily with a ganglion-blocking agent (mecamylamine) than to accelerate the regimen. The action of all blocking agents is variable; if an effective dose of the drug is to be used, inevitably occasions will arise when symptoms of the excessive blockade are experienced, e.g., after an infection, unusual exercise, in hot humid weather or even after a large meal. To help the patient maintain an optimal therapeutic response to the drug, he should be made aware of the symptoms he may encounter and how to deal with them.

In view of the inevitable fluctuations in pressure with autonomic blocking agents, they should be used with care in patients with advanced coronary or cerebrovascular diseases. However, they are not necessarily contraindicated in these conditions when severe hypertension is present; in fact, angina may be relieved as effective control of blood pressure is achieved. ${ }^{27}$

\section{SumMary}

Both reserpine and guanethidine appear to utilize the same fundamental pharmacological mode of action which leads to depletion of tissue catecholamines.

Guanethidine produces effects on the blood pressure similar to those of the ganglion-blocking agents without the troublesone side effects. It is an extremely potent agent, however, and is likely to produce symptoms attributable to postural hypotension.

\section{ReFERENCES}

1. Burn, J. H. and Rand, M. J. Reserpine and noradrenaline in artery walls. Lancet, 2: 1097, 1957.

2. Rropif, B. B., Shore, P. A. and Hess, S. M. Persistence of reserpine action after the disappearance of drug from the brain: Effect of serotonin. Ann. N. Y. Acad. Sc., 66: 631, 1957.

3. Maxwell, R. A., Mull, R. P. and Plummer, A. J. [2-(octahydro-1 -agocinyl)- ethyl]-guanethidine sulphate (SU 4029) a new synthetic antihypertensive agent. Experientia, 15:267, 1959.

4. Maxweli, R. A., Plummer, A. J., Schneider, F., Povaski, H. and Daniel, J. J. Pharmacology of [2-(octahydro-1-agocinyl)-ethyl] guanethidine sulfate (SU 5864). J. Pharmacol. \& Exper. Therap., 128: 22, 1960 . 
5. Panronen, M. K. and Krayer, $U$. The relcase of norepinephrine from the mammalian heart by reserpine. J. Pharmacol. \& Exper. Thernp., 123: $153,1958$.

6. Muscholl, $\mathrm{E}$. and Vogt, M. The concentration of adrenalin in the plasma of rabbits treated with reserpine. Brit. J. Pharmacol., 12: 532, 1958.

7. Burn, J. H. and RAND, M. J. The action of sympathomimetic amines in animals treated with reserpine. J. Physiol., 144: 314, 1958.

8. Burn, J. H. and RAND, M. J. Noradrenaline in artery walls and its dispersal by reserpine. Brit. M. J., 1: 903, 1958 .

9. Maxwell, R. A., Plummer, A. J., Povalski, H. and Sulneider, F. Concerning a pussible action of guanethidine in smooth muscles. J. Pharmacol. E Exper. Therap., 129: 24, 1960.

10. Ciass, R., Kuntzman, R. and Brodie, B. Norepinephrine depletion as a possible mechanism of action of guanethidine, a new hypertensive agent. Proc. Soc. Exper. Biol., \& Med., 103: 871, 1960.

11. Hozbauer, M. and Vogt, M. Depression by reserpine of the noradrenaline concentration in the hypothalamus of the cat. I. Neurochem., 1:8, 1956.

12. Plesgher, A., Shore, P. and Brodif, B. Scrotonin release as a possible mechanism of rescrpine action. Science, 122: 374, 1955.

13. Gaunt, R., Renzi, A., Antonchak, N., Miller, G. and Gluman, M. Endocrine aspects of the pharmacology of reserpine. Ann. N.Y.Acad. Sc., 59:22, 1954.

14. Plummer, $\Lambda$. J., Schneider, J. A., 'Trapold, J. and BarretT, W. Pharmacology of rauwolfia alkaloids, including reserpine. Ann. N. Y. Acad. Sc., 59: 8, 1954.

15. Brodie, B. B. Effects of chlorpromazinc, reserpine and monoamine oxidase inhibitors on the cardiovascular system by interaction with central and peripheral neurohumoral agents. Iroc. High Blood Pressure Council, 7: 83, 1959.
16. Slleldon, M. B. and Kotte, J. H. K. The effects of rauwolfia serpentina and reserpine on the blood pressure in essential hypertension. Circulalion, 16: 200, 1957.

17. Cooper, E. H. and Cranston, W. I. A comparison of the effects of phenobarbitone reserpine in hypertension. Lancet, 1:396, 1957.

18. Donald, K. Exercise studies in heart disease. Mod. Concepts Ciardiovas. Dis., 28: 529, 1959.

19. Moyer, J. H. Cardiovascular and renal hemodynamic responsc to reserpine (Serpasil) and clinical results of using this agent for the treatment of hypertension. Ann. N.Y.Acad. Sc., 59: 82, 1954.

20. Hafkensghiel, J. M., Sellfers, A. M., King, G. A. and Thorner, M. W. Preliminary observations of the effects of parenteral reserpine on cerebral blood flow, oxygen and glucose metabolism, and electroencephalograms of patients with essential hypertension. Ann. N. Y. Acad. Sc., 61: 78, 1953.

21. Jollery, C. T., Emslie-Smith, P. and Melue, M. D. Clinical and pharmacological studies with guanethidine and the treatment of hypertension. Lancet, 2: 381, 1960.

2.). Righardson, D. W., Wyso, F. M., Magfe, J. H. and Cavell, G. C. Circulatory effects $0^{\circ}$ guanethidine. Circulation, 22:184, 1960.

23. Ijeishman, A. W. D., Mathews, H. L. and Smith, A. J. Guanethidine: hypotensive drug with prolonged action. Lancet, 2: 1044, 1959.

24. Dollery, G. T., Emslie-Smith, D. and ShillingFORD, J. P. Hemodynamic effects of guanethidine. Lancet, 2: 331, 1961.

25. Lauwers, P., Conway, J. and Hoobler, S. IT. La guanethidine dans le traitment de l'hypertension arterielle. Acla cardiol., 16:221, 1961.

26. Page, I. H. and Dustan, H. P. A new potent antihypertensive drug. J.A.M.A., 170: 1265, 1959.

27. Geogopaulos, A. J., Jones, F. M., JR. and Page, I. H. Relationship between arterial pressure and exertional angina in hypertensive patients. Cir culation, 23: 892, 1961. 